\title{
Local injection, naproxen, and simple analgesia led to similar 1 year rates of symptom relief in lateral epicondylitis
}

Hay EM, Paterson SM, Lewis M, et al. Pragmatic randomised controlled trial of local corticosteroid injection and
naproxen for treatment of lateral epicondylitis of elbow in primary care. BMJ 1999 Oct 9:319:964-8.

QUESTION: In adults with lateral epicondylitis (tennis elbow), which of 3 regimens (local corticosteroid injection, 2 weeks of naproxen, or simple analgesia) is most effective?

\section{Design}

Randomised \{allocation concealed*\}†, blinded (outcome assessor and statistician),* placebo controlled trial with 12 months follow up.

\section{Setting}

23 primary care practices in North Staffordshire and South Cheshire, England.

\section{Patients}

164 patients who were $18-70$ years of age $(66 \% \geq 45 \mathrm{y}$, $52 \%$ men) and had consulted their general practitioner because they had had a new episode of lateral epicondylitis. Exclusion criteria were a history of inflammatory arthritis or gross structural abnormality of the elbow, contraindications to non-steroidal antiinflammatory drugs (NSAIDs) or local steroid injection, pregnancy, or breast feeding. 98\% of patients were included in the analysis for 4 week complete recovery, $96 \%$ for 4 week and 12 month pain severity, and $98 \%$ for 6 month pain severity.

\section{Intervention}

Patients were allocated to a local corticosteroid injection of methylprednisolone, $20 \mathrm{mg}$, and $1 \%$ lignocaine, 0.5 $\mathrm{ml}(\mathrm{n}=53)$; enteric coated naproxen, $500 \mathrm{mg}$ twice daily for 2 weeks $(n=53)$; or placebo for 2 weeks $(n=58)$. Patients received co-codamol (a combination of paracetamol [acetaminophen] and codeine, $8 \mathrm{mg}$ ) for additional pain relief.

\section{Main outcome measure}

Patients' global assessment of change (5 point scale). Secondary outcomes included pain severity (10 point Likert scale).

\section{Main results}

Analysis was by intention to treat. More patients in the injection group than in the naproxen or placebo groups reported complete recovery and had pain scores $\leqslant 3$ at 4 weeks ( $\mathrm{p}<0.05$ for all comparisons) (table). At 6 months, fewer patients in the injection group than in the placebo group had pain scores $\leqslant 3(\mathrm{p}<0.05)$ (table). At 12 months, $\geq 80 \%$ of patients in each group had pain scores $\leqslant 3$.

Local corticosteroid injection (inj), naproxen (nap), and placebo (pl) for lateral epicondylitis

\begin{tabular}{|c|c|c|c|c|}
\hline Outcomes & Comparisons & Event rates & RBI $(95 \%$ CI) & NNT (Cl) \\
\hline \multirow[b]{2}{*}{ Complete recovery at 4 weeks } & $\operatorname{Inj} v$ nap & $42 \% \vee 5.7 \%$ & $647 \%$ (161 to 2158$)$ & 3 (2 to 5 ) \\
\hline & Inj $v \mathrm{pl}$ & $42 \% \vee 3.6 \%$ & $1085 \%$ (235 to 4321$)$ & 3 (2 to 5 ) \\
\hline \multirow{3}{*}{ Pain scores $\leqslant 3$ at 4 weeks } & $\operatorname{Inj} v$ nap & $82 \%$ v $48 \%$ & $71 \%$ (27 to 138$)$ & 3 (2 to 7$)$ \\
\hline & Inj $v \mathrm{pl}$ & $82 \%$ v $50 \%$ & $64 \%(24$ to 124$)$ & 4 (3 to 8 ) \\
\hline & & & RBR (CI) & NNH (CI) \\
\hline Pain scores $\leqslant 3$ at 6 months & $\operatorname{lnj} v \mathrm{pl}$ & $65 \%$ v $83 \%$ & $22 \%$ (2 to 39 ) & 6 (3 to 89$)$ \\
\hline
\end{tabular}

₹RBR = relative benefit reduction. Other abbreviations defined in glossary; RBI, NNT, RBR, NNH, and Cl calculated from data in article.

\section{Conclusions}

In patients with acute lateral epicondylitis, local corticosteroid injection was most effective for relieving sympinjection, naproxen, and simple analgesia led to similar rates of symptom relief.

*See glossary.

†Information provided by author.

\section{COMMENTARY}

This pragmatic randomised controlled trial by Hay et al, in which primary care patients were followed up for 1 year, overcomes many of the limitations of previous trials, ${ }^{1}$ and allows some realistic clinical conclusions to be drawn.

This study confirms that a local injection of methylprednisolone, $20 \mathrm{mg}$, and lignocaine is effective in the treatment of lateral epicondylitis, providing short term relief from pain. However, some patients who respond well to injection will probably relapse by 6 months.

On the other hand, NSAID treatment, in the form of naproxen, $500 \mathrm{mg}$ twice daily for 2 weeks, fared no better than placebo at any point during follow up. Some $30 \%$ of patients randomly allocated to the naproxen and placebo treatment groups received a corticosteroid injection during the follow up period. In view of the lack of evidence that 1 form of NSAID performs any better than another or that NSAIDs are more effective than simple analgesics, NSAIDs apparently have no role in treating tennis elbow. ${ }^{2}$

No matter what treatment was given-local injection, NSAID, or placebo-the outcome at 1 year was similar, with almost all patients making a satisfactory recovery. The remaining question is: what role, if any, does physical therapy have in the treatment of lateral epicondylitis?

Anthony S Dixon, $\mathrm{MBChB}$ University of Hong Kong Hong Kong, China

1 Assendelft WJ, Hay EM, Adshead R, et al. Corticosteroid injections for lateral epicondylitis: a systematic overview. $\mathrm{Br} J$ Gen Pract 1996;46:209-16.

2 Gotzsche PC. Non-steroidal anti-inflammatory drugs. BMJ 2000;320:1058-61. toms at 4 weeks but not at 6 months. At 1 year, local
Arthritis Research

Campaign. UpJohn

provided

methylprednisolone injections; Syntex

provided enteric coated

naproxen.

For correspondence:

Dr E M Hay,

Staffordshire

Rheumatology Centre,

The Haywood, Burslem

Stoke-on-Trent

ST6 7AG, UK. Fax

+44 (0)1782 412236 